\title{
Ejes y modelos en la etapa actual de la integración económica regional en América Latina
}

\author{
Axes and models in the current scenario of regional \\ economic integration in Latin America
}

José Briceño Ruiz*

\section{Resumen}

Este trabajo se propone revisar el escenario actual de la integración regional en América Latina. En este sentido, se argumenta que en la región existe actualmente una fragmentación de la integración económica en tres ejes: un eje de integración abierta, un eje revisionista y un eje antisistémico. En cada uno de estos ejes se han adoptado distintos modelos económicos de integración. Acudiendo a Max Weber proponemos la existencia de tres tipos ideales de modelos de integración económica: el regionalismo estratégico, el regionalismo productivo y el regionalismo social. En el trabajo se analizan las interacciones existentes entre los ejes y los modelos de integración existentes en la región latinoamericana.

Palabras clave: integración económica, modelos, América Latina, ALBA, Mercosur, Alianza del Pacífico.

\section{Abstract}

This paper analyses the current scenario of regional economic integration in Latin America. Thus, we argue that a fragmentation of regional

Doctor en Ciencia Política del Instituto de Estudios Políticos de Aix-en-Provence, Francia. bricenoruiz@ gmail.com

Recibido el 3 de febrero de 2013. Aceptado el 7 de junio de 2013. 
integration in three axes currently exists in Latin America: an open integration axis, a revisionist axis and an anti-systemic axis. In each of these axes, different models of regional integration have been adopted. By using Max Weber's idea on ideal types, we propose three models of regional integration: strategic regionalism, productive regionalism and social regionalism. In the paper, we examine interactions between the current axis and models of economic integration in Latin America.

KeYwORDs: economic integration, models, Latin America, ALBA, Mercosur, Pacific Alliance. 
José BRICEÑo Ruiz • Ejes y modelos de la etapa actual de la integración económica...

La integración latinoamericana está en una nueva fase de su desarrollo en la que emergen nuevas realidades y se ha roto el consenso en cuanto al modelo de integración que existió en la década de 1990. La denominación de esta nueva etapa es aún objeto de discusión. Autores como José Antonio Sanahuja (2010), Pedro Da Motta Veiga y Sandra Rios (2007), han acuñado la expresión «regionalismo post-liberal», para definir la sustitución del contenido de la agenda de la integración latinoamericana, que pasó de estar centrada en la liberalización del comercio y las inversiones para dar prioridad a objetivos políticos, sociales y productivos. No está claro si para los autores señalados el regionalismo post-liberal es una etapa del regionalismo latinoamericano o un modelo de integración, pero para ellos sí lo está que el periodo del regionalismo abierto concluyó. Pia Rigirozzi, en cambio, prefiere utilizar la expresión «regionalismo post-hegemónico», en el cual se propone realizar una ruptura con el discurso hegemónico durante la década de 1990, que asociaba el regionalismo a los procesos de globalización bajo inspiración de las ideas neoliberales. En ese marco, el regionalismo se percibía como una respuesta defensiva a esos procesos globales. Para Rigirozzi, el regionalismo que se desarrolla en América Latina en el decenio de 2000 intenta ir más allá de ser un mecanismo defensivo y en vez de ello sería más bien un espacio de contestación y resistencia para enfrentar el neo-liberalismo y la hegemonía estadounidense (Rigirozzi, 2010).

En este trabajo se acepta que la integración latinoamericana está viviendo una nueva fase, en la cual varios países han roto claramente con las premisas dominantes durante la etapa del regionalismo abierto. No es fácil indicar cuándo se inicia esta nueva fase, pero sí pueden señalarse algunos momentos críticos, como la firma del Consenso de Buenos Aires en octubre de 2003 por Luiz Ignacio Lula da Silva y Néstor Kirchner, el colapso de la negociación del Area de Libre Comercio de las Américas (ALCA) en la Cumbre de la América realizada en Mar del Plata en noviembre de 2005 o la reunión Cumbre de la Comunidad Sudamericana de Naciones (CASA), realizada en Cochabamba, realizada en diciembre de 2006, en la cual se planteó un amplio debate sobre el modelo de integración que condujo a la transformación de esa iniciativa de integración en la Unión de Naciones Sudamericanas (UNASUR).

Al margen de cuál sea el momento inicial, es claro que el regionalismo latinoamericano atraviesa por un nuevo período, caracterizado por su complejidad, por contradictorios momentos de continuidad y de ruptura con el modelo económico hegemónico en la década de 1990. Igualmente, el nuevo momentum regionalista se define por una compleja agenda, que no se limita a la integración económica (que en el decenio de los noventa privilegió la promoción de zonas de libre comercio o uniones aduaneras), sino que comprende objetivos políticos, 
estratégicos, sociales, además de intentar ampliar la dimensión económica de la integración al incluir objetivos de carácter productivo.

En este trabajo se adopta el concepto de «regionalismo» como la categoría ontológica objeto de análisis. El regionalismo se define como un proceso de tipo asociativo en que se producen en ámbitos espaciales delimitados del sistema internacional, denominadas «macro-regiones» o regiones internacionales. Varios aspectos definen estas regiones. En primer lugar, aunque el elemento de la contigüidad geográfica es una variable para delimitar el regionalismo, esta se suele interpretar de manera algo flexible. Así, las «Américas» es considerada una región, cuya base institucional es la Organización de los Estados Americanos (OEA). No obstante, no existe contigüidad entre todos los países de esta región y su delimitación espacial es más bien dada por la ideas de Western Hemisphere o Hemisferio Occidental, promovidas especialmente por Estados Unidos. Algo similar sucede con el Foro de Cooperación Asia-Pacífico (APEC en sus siglas en inglés), "macro región» en la cual no existe contigüidad geográfica entre todos los países, sino que su ámbito espacial es definido por la noción espacial "Océano Pacífico». En segundo lugar, una «macro región internacional» es socialmente construida. En este sentido, se coincide con Björn Hettne y Fredrik Söderbaum (2000: 38), quienes aseveran que «las regiones son proyectos políticos y sociales, diseñados por actores humanos para proteger o transformar las estructuras existentes». Finalmente, el regionalismo es un proceso que tiene diversas manifestaciones e intensidades. Así, el regionalismo comprende iniciativas de integración económica, de cooperación económica, de integración política o cooperación o concertación política. La intensidad de esas modalidades es variable. Por ejemplo, la integración económica regional puede expresarse desde la forma básica de una zona de libre comercio hasta la unión monetaria, pero incluso puede ir mucho más allá de lo comercial y expresarse en estrategia de desarrollo productivo conjunto.

Con base en estas premisas, se examina el estadio actual del regionalismo latinoamericano. El trabajo se centra en una dimensión específica de este último: la integración económica regional. En este sentido, se argumenta que en la nueva etapa post-liberal-post-hegemónica del regionalismo latinoamericano se observa la existencia de varios ejes de integración regional, que expresan la adopción de distintos modelos económicos, lo que a su vez es resultado de complejos procesos políticos y económicos que están teniendo lugar en la región desde inicios de la primera década del nuevo milenio.

\section{LOS EJES DE LA INTEGRACIÓN ECONÓMICA LATINOAMERICANA}

Ciertamente, como bien señala Roberto Russell (2010), la década 
José Briceño Ruiz • Ejes y modelos de la etapa actual de la integración económica...

de 1990 fue un periodo particular en América Latina, pues hubo cierta homogeneidad sobre la conveniencia de una estrategia de desarrollo basada en el libre mercado y la apertura. Se debe relativizar un poco ese consenso, pues existieron «velocidades» en cuanto a la forma de aplicar esa estrategia. No fue igual el proceso de reforma económica en la Argentina gobernada por Carlos Menem que en el Brasil de Fernando Henrique Cardoso. El consenso y las distintas velocidades existieron en los procesos de integración: aunque todos adoptaron el discurso del «regionalismo abierto", varió la forma en que este efectivamente se aplicó. Así, mientras en el Tratado de Libre Comercio de América del Norte (TLCAN) se optó por un modelo de radical apertura acompañada por normas OMC plus para los temas vinculados con el comercio, en el Mercado Común del Sur (Mercosur), se excluyeron del acuerdo sectores considerados estratégicos y no se adoptaron normas OMC plus. No obstante estos matices, en términos generales en la mayoría de los esquemas regionales creados o relanzados en la década de 1990, el núcleo central de la estrategia de integración era la promoción del libre comercio y la búsqueda de la inserción internacional. Este era el modelo de integración hegemónico y era en torno a este modelo que existía cierta homogeneidad.

En la nueva etapa del regionalismo latinoamericano que se desarrolla a partir de 2003 no existe homogeneidad. En vez de ello se observa una heterogeneidad o fragmentación, expresada en la existencia de varios ejes de integración regional con modelos económicos marcadamente distintos. Puede señalarse que la evidencia histórica demuestra que en la fase del regionalismo abierto también existieron ejes. Así durante el primer lustro de la década de 1990 en el Cono Sur se pudo observar una fuerte regionalización de la interdependencia comercial en torno al Mercosur, al que se sumarían Bolivia y Chile como miembros asociados en 1996, mientras que la región andina se producía una reactivación de la integración andina en torno al dinámico núcleo Caracas-Bogotá (cf. Gutiérrez, 1999). Igualmente, México, Colombia y Venezuela intentaron crear un eje de integración en la Gran Cuenca del Caribe, mediante la creación del Grupo de los Tres (G-3), que se articularía con las iniciativas de cooperación e integración que se desarrollaban en América Central y el Caribe Insular (cf. Giacalone, 1999). No obstante, con sus matices y variantes todos esos ejes compartían un modelo de integración basado en la apertura comercial y la inserción internacional. El escenario actual es diferente, pues no se trata solo de que existen al menos tres ejes de integración, sino que estos proponen diversos modelos de integración, en algunos aspectos contradictorios.

En el presente trabajo se examinan estos distintos ejes de integración y los diversos modelos de integración que propone cada uno de ellos. En este sentido, se propone la existencia 
de tres ejes de integración: el eje del regionalismo abierto; el eje revisionista y el eje antisistémico. Acudiendo al concepto weberiano de tipos ideales, en la sección siguiente, se proponen tres modelos de integración regional: el modelo de regionalismo estratégico, el modelo de regionalismo social y el modelo de regionalismo productivo. En una tercera parte se examina el modelo de integración que ha sido adoptado en cada uno de los ejes actualmente y sus implicaciones para la región. Finalmente, se presentan algunas conclusiones.

Como se observa en la figura 1 , en el actual escenario de la integración latinoamericana pueden observarse tres ejes de integración claramente diferenciados. Estos comenzaron a configurarse desde inicios del nuevo milenio, cuando las transformaciones políticas en la región y el mundo comenzaron a crear condiciones adversas al modelo imperante en la región.

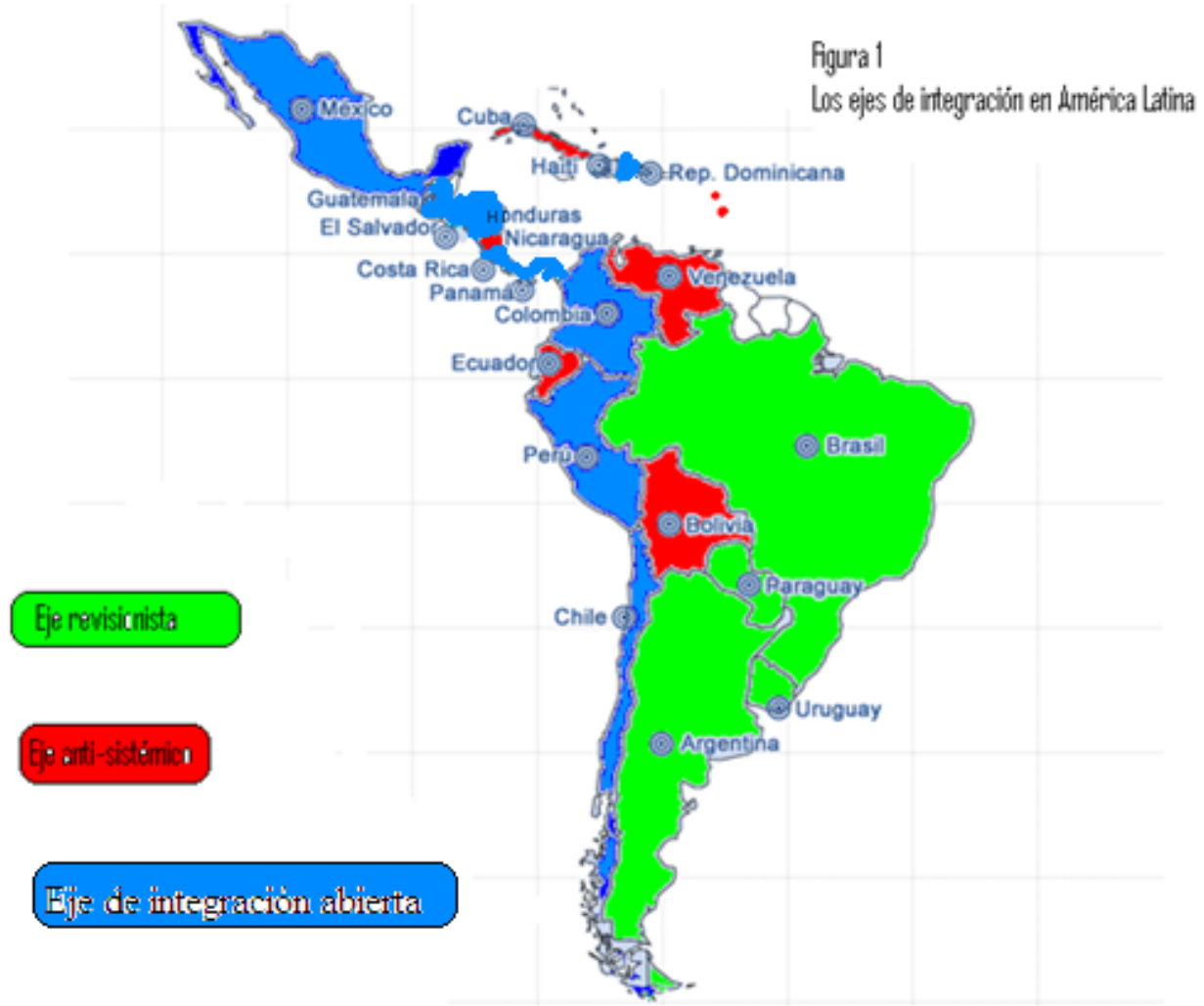


José Briceño Ruiz • Ejes y modelos de la etapa actual de la integración económica...

1.1 El eje de la integración abierta: de los TLC a la Alianza del

\section{Pacifico}

El modelo en que se basa el primer eje, al que denominamos «eje del integración abierta», es el TLCAN suscrito entre Canadá, Estados Unidos y México en 1994. Este es un proceso que constituye un modelo de integración distinto de los modelos tradicionales que se desarrollaron en las oleadas previas de regionalismo económico en las décadas del 1960 y 1970, mostrando diferencias sustanciales con la Unión Europea, el referente externo más importante para los países latinoamericanos.

El TLCAN es una expresión de esta integración abierta, puesto que su objetivo de promover un espacio comercial preferencial no se hace a expensas del sistema multilateral de comercio. Al contrario, la preferencia regional se concibe como un paso previo hacia una mayor apertura global. Sin embargo, el TLCAN corresponde más a una versión del Asia Pacífico del regionalismo abierto que a la propuesta por la CEPAL, pues carece de instrumentos para el fomento de la transformación productiva con equidad. Además de promover una integración regional abierta, el TLCAN plantea la regulación de sectores como la propiedad intelectual, las compras gubernamentales y las normas ambientales y laborales relacionadas con el comercio. Los antiguos procesos de integración no incluirán estas materias. Por otro lado, el TLCAN se presenta como una modalidad de integración
«Norte-Sur», al reunir en su seno a países desarrollados y en vías de desarrollo. Su propulsor principal, Estados Unidos, intentó expandir este modelo mediante el Área de Libre Comercio de las Américas (ALCA) y ante el estancamiento de este proceso ha optado por suscribir tratados bilaterales de libre comercio, como el CAFTA+RD celebrado con los países de América Central y República Dominicana o los TLC firmados con Chile, Perú y Colombia.

A partir de 2007 la mayoría de estos países que han suscrito TLC comenzaron a adoptar una estrategia regional para responder a los críticos del enfoque sobre integración regional dominante en los años 1990. En tal sentido, en 2007 se lanzó el «Foro del Arco del Pacífico Latinoamericano", un grupo regional constituido por Colombia, Costa Rica, Chile, Ecuador, El Salvador, Honduras, Nicaragua y México. Esta iniciativa incluía, por un lado a los países que aún apoyaban el modelo de regionalismo abierto, excepto Nicaragua y Ecuador. Por otro lado, con la excepción de Ecuador, en el Foro se agrupaban todos los países que habían suscrito TLC con Estados Unidos y la Unión Europea.

El Foro se transformó en la Alianza del Pacífico en abril de 2011, cuando solo Colombia, Chile, Perú y México establecieron un nuevo bloque regional orientado a promover la «integración profunda» y el libre comercio (Declaración Presidencial de Lima, 28 de abril de 2011). La Alianza del Pacifico representa una respuesta política de 
los gobiernos latinoamericanos que todavía apoyan el modelo de integración abierta, es una reacción al creciente protagonismo del eje del ALBA y del gobierno de Hugo Chávez en el escenario de la integración económica en América Latina. El nuevo bloque se propone buscar también ser un factor de equilibrio frente al cada vez mayor liderazgo brasilero en América del Sur, sea en su accionar unilateral o en el marco del Mercosur. Finalmente, se argumenta que la Alianza constituye un mecanismo para negociar en común con los países del Pacífico (véase Briceño Ruiz, 2012).

\subsection{El eje revisionista}

Desde sus inicios el Mercosur fue un modelo híbrido, que aunque nació con elementos típicos del «regionalismo abierto», en particular su énfasis inicial en la apertura y desgravación comercial, al mismo tiempo careció de una agenda de «integración profunda». El Mercosur combinó un proceso de apertura sin «integración profunda» con la ausencia de mecanismos para avanzar en la integración social y productiva. Sin embargo, desde el año 2003 ha comenzado a revisar este modelo de integración para crear y fortalecer los aspectos sociales y productivos en el bloque regional, proceso de revisión que se mantiene incluso en nuestros días.

El Tratado de Asunción, estableció como objetivos el perfeccionamiento de una zona de libre comercio y la adopción de un arancel externo común, aunque se admitía la posibilidad de acuerdos sectoriales. A pesar de este sesgo "comercialista», el Mercosur no adoptó la modalidad de «integración profunda», pues si bien se propuso normar aspectos como la propiedad intelectual o las compras gubernamentales, no se planteó hacerlo aprobando normas de tipo OMC plus. De igual manera, aunque en el Tratado de Asunción no se consideró la dimensión social, en la década de 1990 el Mercosur logró desarrollar una importante agenda sociolaboral, que condujo a la aprobación de una Declaración al respecto en 1998 y la firma de un acuerdo regional sobre seguridad social ese mismo año. Desde el año 2000, en el Mercosur se ha intentado establecer una sólida dimensión social que transcienda lo meramente laboral. En otras palabras, se trata de la aplicación de políticas redistributivas que se propone proveer a amplios sectores de la población del acceso a educación, salud, vivienda y servicios públicos de calidad. Son medidas típicas del Estado de bienestar, dirigidas a reducir la pobreza, redistribuir la riqueza, promover la justicia social y reglamentar las instituciones de mercado. Expresión de este proceso es la creación de instancias como la Reunión de Ministros y Autoridades de Desarrollo Social en 2000, la creación del Instituto Social del Mercosur en 2007 y la aprobación en 2008 del Plan Estratégico de Acción Social del Mercosur.

De igual manera, el Mercosur ha venido gradualmente rescatando la idea 
José Briceño Ruiz • Ejes y modelos de la etapa actual de la integración económica...

de convertir la integración regional en un mecanismo para promover la integración productiva, en particular la industrialización. Se están apenas dando los primeros pasos en esta dimensión productiva del Mercosur al adoptarse un Programa Regional de Integración Productiva (2008), aprobarse un fondo de apoyo a las PYMES (2008) y comenzar a tratarse las asimetrías productivas, mediante la creación en 2005 de un Fondo de Convergencia Estructural (FOCEM).

El proceso de revisión del modelo de integración económico del Mercosur se ha acompañado de la construcción de un nuevo regionalismo sudamericano, en el cual Brasil ha tenido un liderazgo. En sus inicios, el proceso tenía en esencia un contenido comercial en la estricta lógica de la apertura y el regionalismo abierto, cuya expresión era la constitución de una Área Sudamericana de Libre Comercio (ALCSA), resultado de la convergencia entre la Comunidad Andina (CAN) y el Mercosur. Sin embargo, luego surgieron propuestas más allá de lo comercial. En 2000 el objetivo de crear un ALCSA se sustituyó por la más ambiciosa meta de establecer una Comunidad Sudamericana de Naciones (CASA), que además de la convergencia comercial entre la CAN y el Mercosur, se proponía el desarrollo de la infraestructura regional sudamericana, la cooperación contra el crimen organizado, en particular el tráfico de drogas, y la consolidación de América del Sur como zona de paz. En 2007, CASA se transforma la UNASUR, proyecto mucho más ambicioso con objetivos en las esferas ambiental, social, política y de seguridad. La UNASUR es parte del proceso de revisión del regionalismo en América Latina, pero no es una iniciativa de integración económica. Por ello, no se puede ubicar en los modelos descritos en esta sección de este trabajo. En consecuencia, no es objeto de análisis en este artículo.

\subsection{El eje anti-sistémico}

Al menos según los documentos y discursos de los líderes de sus países miembros el ALBA representa un modelo de integración anti-capitalista y anti-imperialista. El nuevo esquema de integración fue anunciado por Hugo Chávez en diciembre de 2001 durante la III Cumbre de la Asociación de Estados del Caribe (AEC), bajo el nombre de Alternativa Bolivariana para las Américas (ALBA), como una iniciativa que planteaba promover un modelo nuevo de integración basado en la solidaridad, la complementariedad y la cooperación.

En sus inicios, la propuesta ALBA careció de mayor contenido, pero a partir del año 2002 se presentó como una alternativa al ALCA que impulsaba Estados Unidos y, en este sentido, se dieron a conocer varios documentos oficiales en los cuales se contrastaban las propuestas de negociación que se estaban realizando en el marco de la negociación hemisférica con lo planteado por el ALBA. En abril de 2004, en un encuentro realizado en La Habana, 
Hugo Chávez, Fidel Castro y Evo Morales, relanzan la propuesta, que deja de ser simplemente una alternativa al ALCA. Incluso se ha cambiado el significado de la sigla ALBA, que ha pasado a significar la Alternativa Bolivariana para la América, a veces, la Alternativa Bolivariana para nuestra América y más recientemente Alianza Bolivariana de los Pueblos de América (cf. Briceño Ruiz, 2011). En su fase más reciente, el ALBA comienza a consolidarse como iniciativa regional, presentándose como una modalidad de integración no capitalista y distinta del modelo de integración abierta. Incluso, se le ha presentado como un elemento de la lucha mundial contra el imperialismo (Martínez, 2006: 66-87).

Algunos autores argumentan que el ALBA no puede considerarse una iniciativa de integración económica sino un espacio de cooperación económica y política (Buck, 2010: 397). Es posible que esta afirmación sea válida para explicar los primeros años del ALBA, pero desconoce la evolución de esta iniciativa. El ALBA ha incluido en su agenda temas como la formación de empresas Gran-nacionales, algunas de la cuales se proponen desarrollar proyectos industriales en conjunto. Esto constituye claramente una forma de integración económica. Más recientemente, en el seno del bloque se ha planteado la creación de la zona económica del ALBA (conocida como Eco ALBA). Ahora bien, el ALBA no es una forma tradicional de integración económica, sino que plantea que esta se desarrolle no a partir de una estrategia tradicional basada en el libre comercio, sino que, como se analiza en la próxima sección, propone un nuevo modelo de integración económica no capitalista.

\section{LOS MODELOS DE INTEGRACIÓN ECONÓMICA EN AmÉrica Latina}

En esta sección se analizan los modelos de integración que pueden observarse en los distintos ejes de la integración económica latinoamericana. Acudiendo a la noción weberiana de tipo ideal, se argumenta que existen tres tipos ideales o modelos económicos que han sido adoptados en los diversos ejes de integración regional: el modelo de regionalismo estratégico, el modelo de regionalismo social y el modelo de regionalismo productivo. La extensión de este trabajo no nos permite un análisis exhaustivo de estos tres modelos de integración, pero, presentan sus rasgos fundamentales, de manera de poder aplicarlos posteriormente a los diversos ejes de integración existentes actualmente en América Latina.

El uso de las expresiones «estratégico» y estrategia no ha sido de uso amplio en los estudios de integración regional, es mucho más frecuente en los estudios sobre la guerra y el conflicto. Así, Bernard Brodie (2008: 13) argumenta que la estrategia «está dedicada a descubrir cómo los recursos humanos y materiales de una nación pueden ser desarrollados y utilizados con el fin maximizar la efec- 
José BRICEÑo Ruiz • Ejes y modelos de la etapa actual de la integración económica...

tividad total de la nación en la guerra». En un sentido militar más limitado, «la estrategia se relaciona con los recursos movilizados y se concentra en el logro de una victoria sobre un enemigo especifico bajo un conjunto de circunstancias políticas y geográficas» (Brodie, 2008: 13).

Este uso casi exclusivamente militar dado a la "estrategia» y lo "estratégico", hace que la expresión genere reservas en el campo de los estudios sobre regionalismo internacional, porque se puede dar la impresión de que lo está concibiendo como instrumento de una «guerra económica». Esta es una noción ya presente en los trabajos de Federico List, Carlos Marx y Alberto Hirschman, aunque ellos no utilizasen la expresión en sí, que apenas comienza a aparecer en textos más recientes, aunque sin una definición clara. En general, la expresión «guerra económica» describe «una competencia económica internacional exacerbada, mediante el uso de medidas injustas por los gobiernos, en particular estrategias de tipo «begar-thy-neighour» (Coulomb, 2004: 252). El problema de esta definición es que no distingue entre guerra económica y competencia económica. En realidad, en esta ultima los Estados buscan es mejorar su posición relativa en la economía mundial y no destruir a sus rivales (Coulomb, 2004: 252). El regionalismo estratégico, como cualquier forma de regionalismo, es un tipo de relación asociativa en el sistema internacional, por lo que su interpretación mediante instrumentos que explican la «guerra económica» no es correcta.
El modelo del regionalismo estratégico se concibe como una «regionalización» de la denominada "política comercial estratégica» que comienza a desarrollarse en la década de los años ochenta del siglo XX. Esta última se basó en las premisas de la nueva teoría del comercio internacional sobre la existencia de ciertos sectores en los cuales predominan formas de competencia monopólica y sobre la existencia de determinados sectores que, por ser considerados estratégicos, merecen especial atención de los Estados (véase Brander, 2005; Richardson 1990, 1992).

El modelo de regionalismo estratégico se distingue por su marcado sesgo comercial. Este modelo ha proliferado en la nueva oleada de integración que se inició a fines de <la década de 1980 e inicios de la década de 1990 y se considera como expresión del denominado nuevo regionalismo. Uno de sus pilares es la apertura de la región integrada a la economía internacional, pues se muestra en principio como una forma de «regionalismo abierto». Así, el libre comercio es un importante componente de este modelo. Sin embargo, como en el caso de la política comercial estratégica, los sectores que se consideran importantes para el desarrollo económico de los países del bloque son excluidos de este régimen global de libre comercio.

El regionalismo estratégico se desarrolla com<o respuesta de los Estados, en alianza con las empresas transnacionales (ETN) al escenario global de 
la postguerra fría, uno de cuyos componentes es la proliferación de bloques económicos. Se trataría entonces de un elemento de la estrategia de algunos países para "administrar» de manera más coherente el proceso de globalización y la creciente regionalización del comercio que la acompaña. Una de las formas de «administrar» estos procesos es mediante la promulgación de una agenda de «integración profunda». Este es un concepto elaborado por Robert Lawrence, para quien los tradicionales acuerdos de integración se proponían apenas facilitar el acceso a los mercados mediante la desgravación arancelaria y la eliminación de las barreras no arancelarias que impidan la libre circulación de bienes y servicios. Esta era una «integración superficial». No obstante, en un contexto de apertura comercial y globalización financiera, Lawrence consideraba necesario profundizar la agenda de integración para incluir elementos que «están relacionados con el comercio", como las inversiones, la propiedad intelectual, las compras gubernamentales y las normas laborales y ambientales. En consecuencia, estos temas deben ser parte de las nuevas iniciativas de integración regional (Cf. Lawrence, 1996).

Ahora bien, la profundidad y amplitud de esta «integración profunda» depende de si se trata de un «acuerdo norte-sur» o de un «acuerdo sur-sur». En los primeros, es decir en iniciativas de integración que incluyen a países desarrollados y en vías de desarrollo, les interesa promover una agenda de integración profunda y exigen que los países del adopten normas sobre inversiones, servicios o propiedad intelectual como pay off por el mayor ingreso a sus mercados. En los «acuerdo sur-sur», es decir, los que solo incluyen a países en vías de desarrollo, aunque algunos de ellos sean considerados emergentes, existe menor tendencia a una agenda de «integración profunda».

Como señala, Andrew Axline, uno de los primeros en utilizar el concepto de regionalismo estratégico, este se compone de un conjunto de respuestas estratégicas de los Estados a las fuerzas de la globalización, que sería utilizado para desarrollar una estrategia mercantilista para beneficiarse de los cambios en las ventajas comparativas, al otorgar a sus empresas una posición privilegiada en la economía mundial (cf. Axline, 1999). También el canadiense David Mercier define el regionalismo estratégico en la medida en que este se propone controlar la globalización, es decir, intenta consolidar la seguridad económica entre los países que participan en estos acuerdos para que puedan enfrentar la competencia global (Mercier, 2000: 115-116).

Nuestro enfoque es que aunque el Estado es un actor crucial en la formulación del regionalismo estratégico, las ETN, incluso aquellas de los países emergentes, también cumplen una función decisiva en su diseño. El regionalismo estratégico es un proceso que resulta de una alianza entre Estados nación y empresas multinacionales o empresas nacionales que han comenza- 
José Briceño Ruiz • Ejes y modelos de la etapa actual de la integración económica...

do el proceso de internacionalización de sus actividades económicas. Como ya se indicó, el antecedente del regionalismo estratégico es la política comercial estratégica, una modalidad de política comercial desarrollada por la nueva teoría del comercio internacional para describir el funcionamiento de determinados mercados oligopólicos. Se entendía que existían ciertos sectores, como la industria de la aviación, que necesitaban de algún tipo de intervención del Estado, que apoyaría a los sectores privados, en principio, responsables de su desarrollo. La política comercial estratégica comenzó a promoverse en Estados Unidos y otros países desarrollados en la década de 1980, cuando se estableció una alianza entre los Estados y las ETN, cuya sede principal estaba en estos países.

Al final de la década de 1980 y durante los años 1990, la creciente competencia intraempresa, condujo a las ETN a aumentar el lobby ante los gobiernos en pro de la adopción de medidas que eviten el deterioro de su influencia en ciertas regiones o países. Para un Estado apoyar a sus empresas también era un mecanismo para evitar la disminución de sus capacidades o que el aumento de las ganancias obtenidas por otras ETN cuya sede central se encuentra en otro Estado a expensas suyas. Entonces, la política comercial estratégica se transformó en regionalismo estratégico y la integración regional comenzó a utilizarse como mecanismo para promover los intereses de la alianza Estado nación- ETN.
Frente al predominio del enfoque del regionalismo estratégico, desde hace algunos años se ha venido planteando la necesidad de fomentar un regionalismo social, en particular, en los trabajos de Nicola Yeates (2005) y Bob Deacon et al. (2007) y Pia Riggirozzi (2012). Estos autores proponen que la integración regional no sea solamente un mecanismo para construir un espacio comercial o de promoción de las inversiones, sino como un espacio para construir y aplicar una política social regional. La integración se concibe como un mecanismo para establecer estándares sociales a escala regional, fomentar políticas redistributivas e incluso crear instituciones que permitan a los ciudadanos hacer valer sus derechos sociales. Mediante la aplicación de esta política social regional se establecerían medidas para reducir los efectos negativos que genera la apertura comercial en un proceso de integración y se aprobarían mecanismos para reducir las asimetrías existentes entre los países y al interior de estos. Mariana Vázquez (2011: 184) ha acuñado la expresión «regionalismo inclusivo" para describir la nueva etapa del Mercosur, en la cual destaca la construcción de una sólida dimensión social de la integración, concebida no solo como una respuesta a los desequilibrios nacionales y regionales causados por la apertura comercial sino más bien entendida como un estrategia regional para resolver la histórica deuda social de muchas sociedades latinoamericanas. Esta idea de «regionalismo inclusivo» 
es muy cercana al modelo de regionalismo social.

El tercer modelo de integración, descrito como "regionalismo productivo", retoma alguna de las premisas vigente durante el periodo del regionalismo autonómico latinoamericano de la década del sesenta (véase Briceño Ruiz, 2001, 2007). Este modelo se remonta a las ideas de la escuela estructuralista de la Comisión Económica para América Latina (CEPAL) (Prebisch 1959; CEPAL, 1959) y el estructuralismo francés (Perroux 1966; Marchal, 1965, 1970), de utilizar la integración como parte de la estrategia de transformación productiva regional. En años recientes se ha visto un renacer de estas propuestas por parte de instituciones como la Conferencia de las Naciones Unidas sobre Comercio y Desarrollo (UNCTAD, 2007). En el modelo de integración productiva el objetivo es el fomento de un desarrollo industrial conjunto y la unificación de las economías sobre la base del principio de la solidaridad. Ahora bien, este modelo no propone exactamente un regreso a una estrategia de "crecimiento hacia adentro", sino que se acerca más a lo que el especialista Osvaldo Sunkel (1991) describe como «crecimiento desde dentro». Eso supone utilizar las capacidades endógenas y los recursos nacionales para promover la diversificación productiva, en particular, la industrialización, pero partiendo de la premisa que este proceso no está en contradicción con la conquista de mercados mundiales y la atracción de las inversiones extranjeras. Por esto, el modelo del regionalismo productivo no propone solamente la promoción de grandes proyectos industriales que impliquen una fuerte participación del Estado, sino también políticas como la creación de cadenas productivas en la cuales participen empresas locales, nacionales, regionales y transnacionales.

Estos tres modelos de integración responden a motivaciones económicas y políticas muy diversas. El tipo de actor que los promueve también es muy diverso, así como la lógica de acción política que utilizan. Igualmente, es diferente la agenda de integración. Estas diferencias se pueden observar en la cuadro 1.

Finalmente, estos tres modelos de integración pueden presentarse de forma pura o combinada. Así, un proceso de integración regional puede optar por un modelo de regionalismo estratégico puro. Tal es el caso del TLCAN, que es un ejemplo paradigmático de regionalismo estratégico norte-sur. En otros casos, en cambio, se observa que se ha optado por un modelo hibrido, en el que subsisten elementos de los tres modelos arriba explicados. En la siguiente sección se analiza cómo se presentan estos modelos de integración en los ejes actualmente existentes en América Latina. 
José Briceño RuIZ • Ejes y modelos de la etapa actual de la integración económica...

Cuadro 1: Los modelos de integración

\begin{tabular}{|c|c|c|c|c|c|}
\hline & $\begin{array}{l}\text { Motiva- } \\
\text { CIÓN POLÍ- } \\
\text { TICA }\end{array}$ & $\begin{array}{c}\text { Moti- } \\
\text { VACIÓN } \\
\text { ECONÓMI- } \\
\text { CA } \\
\end{array}$ & AgENDA & $\begin{array}{l}\text { Lógica de } \\
\text { Acción }\end{array}$ & Actores \\
\hline $\begin{array}{l}\text { Regionalis- } \\
\text { mo estraté- } \\
\text { gico }\end{array}$ & $\begin{array}{l}\text { Poder Au- } \\
\text { tonomía }\end{array}$ & $\begin{array}{l}\text { Bienestar } \\
\text { Ganancia }\end{array}$ & $\begin{array}{l}\text { Liberalización } \\
\text { comercial + regu- } \\
\text { lación de los temas } \\
\text { relacionados con el } \\
\text { comercio } \\
\text { Exclusión de sec- } \\
\text { tores estratégicos }\end{array}$ & $\begin{array}{l}\text { Nacional + } \\
\text { internacio- } \\
\text { nal } \\
\text { (doble nivel) }\end{array}$ & $\begin{array}{l}\text { Estados con orienta- } \\
\text { ción globalista } \\
\text { ETN } \\
\text { Empresas nacionales } \\
\text { en fase de internacio- } \\
\text { nalización }\end{array}$ \\
\hline $\begin{array}{l}\text { Regionalis- } \\
\text { mo produc- } \\
\text { tivo }\end{array}$ & Autonomía & $\begin{array}{l}\text { Desarrollo } \\
\text { económico }\end{array}$ & Industrialización & Nacional & $\begin{array}{l}\text { Estados con orienta- } \\
\text { ción nacionalista } \\
\text { Actores económicos } \\
\text { nacionales no inter- } \\
\text { nacionalizados }\end{array}$ \\
\hline $\begin{array}{l}\text { Regionalis- } \\
\text { mo social }\end{array}$ & Protesta & Equidad & Política social & $\begin{array}{l}\text { Transnacio- } \\
\text { nal }\end{array}$ & $\begin{array}{l}\text { Ciertas organiza- } \\
\text { ciones internacio- } \\
\text { nales } \\
\text { Estados con orienta- } \\
\text { ción socialista } \\
\text { Sociedad civil }\end{array}$ \\
\hline
\end{tabular}

Fuente: elaboración propia.

3. EJES Y MODELOS DE

INTEGRACIÓN EN LA

ETAPA POSTLIBERAL -

POSTHEGEMÓNICA

En el complejo escenario actual de la integración regional en América Latina existe una estrecha relación entre los ejes de integración realmente existentes. A riesgo de simplificar el escenario actual por razones explicativas, el panorama actual nos muestra tres escenarios: el eje de regionalismo abierto opta por un modelo de regionalismo estratégico, aunque inspirado en el modelo nortesur del TLCAN. El eje revisionista sufre la transformación de un modelo de regionalismo estratégico a un hibrido que incluye elementos de los modelos de regionalismo social y productivo. El eje antisistémico, aunque propone políticas propias del modelo de regionalismo social y, en cierto grado, del regionalismo productivo, al mismo 
tiempo se concibe como un modelo no capitalista. Esto excluiría al ALBA de los modelos de integración conocidos, salvo que se le asimile al fenecido proyecto de integración no capitalista del Consejo de Ayuda Mutua Económica (COMECON).

\subsection{La revisión del modelo de integración del Mercosur}

El Mercosur adoptó originalmente el modelo de regionalismo estratégico. El Tratado de Asunción se propuso esencialmente establecer una zona de libre comercio y una unión aduanera, a lo que se sumaba la exclusión de dos sectores considerados estratégicos: los automóviles y el azúcar. Esto se completaba con la inclusión en listas de excepción de una serie de productos sensibles, como los bienes de capital, cuya desgravación comercial sería más lenta.

Como se explicó en la sección 2 de este artículo, durante la década de 1990 se produjo una reacción de sectores sociales e incluso de instancias gubernamentales para dotar al Mercosur de aspectos sociolaborales y educativos, áreas en las cuales se realizaron progresos importantes. No obstante, en general la evolución de ambas esferas se baso en un enfoque que se proponía compensar las pérdidas causadas por la apertura comercial, por ejemplo, en el ámbito laboral. Por ello, se puede afirmar que a pesar de estos avances en la dimensión social, el proyecto inicial del
Mercosur se enmarcaba en el modelo del regionalismo estratégico.

A partir del Consenso de Buenos Aires, el liderazgo regional optó por revisar el modelo de regionalismo estratégico que predominó en los años 1990. La inclusión de objetivos sociales y productivos expresa la opción por una reforma del modelo de regionalismo estratégico y su énfasis en lo exclusivamente comercial. Este abandono de un modelo puramente comercial se confirma por la negativa del bloque regional a iniciar negociaciones para firmar un acuerdo de libre comercio con Estados Unidos. Aunque el gobierno de Tabaré Vázquez (2005-2010) en Uruguay intentó iniciar negociaciones con Washington, el amplio debate que se produjo en los socios del Mercosur dejó claro que, si no se hacía en marco del Mercosur, la firma de un TLC, suponía abandonar el bloque regional.

Sin embargo, la ruptura con un modelo de regionalismo estratégico no ha significado que se haya adoptado la estrategia de ruptura que propone el eje antisistémico del ALBA. En el Mercosur se ha preservado la dimensión comercial establecida en el Tratado de Asunción. Ciertamente, existen aún tareas pendientes en esta dimensión, por ejemplo, el mantenimiento de la irregular figura de una "unión aduanera imperfecta» y algunas acciones bilaterales que constituyen violaciones a la zona de libre comercio. Además, el intercambio comercial, fuertemente reducido desde la crisis del real y el default argentino, se ha ido recuperando 
José BRICEÑo Ruiz • Ejes y modelos de la etapa actual de la integración económica...

de forma significativa. A pesar de que la importancia del mercado regional varía para cada país y algunos de ellos se han beneficiado más ampliamente de la zona de libre comercio, lo cierto es que «las exportaciones entre los cuatro países aumentaron casi seis veces en valor entre inicios de la década de 1990 y fines de la década siguiente. Esto supera el aumento de poco más de cuatro veces de las exportaciones mundiales totales durante el mismo periodo» (Baumann, 2011: 169). Esto no implica que el Mercosur sea totalmente una historia exitosa en términos comerciales, pues la intensidad de la interdependencia continúa siendo muy baja, representando en 2008 apenas el $15.3 \%$ del comercio total del bloque en 1998 (Schelhase, 2011: 179). La intensidad de la interdependencia es un incentivo clave para promover la cooperación y reasignar discrecionalidad en el manejo de instrumentos de política (cf. Bouzas, Motta Veiga, Rios, 2010). En consecuencia, si bien es cierto que el comercio intrarregional ha crecido en los 21 años de existencia del Mercosur, la intensidad de la interdependencia es aún baja y esto último evidencia una debilidad estructural de la dimensión comercial del proceso de integración.

El riesgo sería que incluir temas sociales y productivos en la agenda de trabajo pueda generar desinterés en la dimensión comercial y provocar un mayor deterioro de la intensidad de la interdependencia. Sin embargo, se han producido avances en materia comercial, por ejemplo, la aprobación del Código Aduanero del Mercosur, en la Cumbre del Consejo del Mercado Común, realizado en San Juan en julio de 2010 (cf. Bizzozero, 2011: 33). La aprobación del Código se acompañó de la eliminación del cobro doble del arancel y la distribución de forma conjunta de la renta aduanera. La aprobación de estos instrumentos de integración comercial demuestra que a pesar de la diversificación de la agenda del Mercosur, las cuestiones relacionadas con la zona de libre comercio y la unión aduanera continúan siendo ejes centrales del proceso de integración.

De lo anterior se colige que la cuestión comercial continúa siendo un tema fundamental en el Mercosur y la dimensión en que, con susaltibajas, el bloque ha producido, resultados concretos. En otras palabras, aunque el Mercosur ha realizado una revisión de un modelo basado exclusivamente en el comercio, esto no ha significado abandonar su dimensión comercial. Esto separa al Mercosur del eje anti-sistémico del ALBA y su prédica de un modelo de integración que excluye el libre comercio.

No obstante, el Mercosur está haciendo esfuerzos por consolidar una dimensión social y una dimensión productiva, explicadas brevemente en la sección 2. La mayor crítica a este conjunto de iniciativas es simplemente definirlas como «retórica» (Malamud, 2005) o sostener que sirven como fuga hacia adelante para escapar de las dificultades que plantea la dimensión comercial del Mercosur (cf. Abreu, 2005; Almeida, 2007). Se trataría de 
una "pérdida de foco", característica reiterada de los procesos de integración en América Latina, que conduce a su irrelevancia (Bouzas, Motta Veiga, Rios, 2010: 339).

Estas críticas deben ser objeto de sería reflexión por quienes están revisando el modelo de integración del Mercosur. No obstante, existen acciones concretas, muchas veces invisibilizadas. Por ejemplo, el Acuerdo Multilateral de Seguridad Social se está aplicando desde hace varios años. Se han desarrollado experiencias concretas de integración productiva, como en el ámbito de muebles y madera; se están llevando a cabo proyectos financiados con recursos del Fondo de Convergencia Estructural (FOCEM). Puede ser que se critique la viabilidad, sustentabilidad o incluso el impacto real de estas iniciativas en el desarrollo del bloque, pero en ese caso la argumentación no debería ser acusarlas de «retórica» pues existen en la realidad y se están implementando. En segundo lugar, la experiencia del Mercosur en los años recientes, no parece justificar el argumento de la pérdida de foco pues como se dijo, el tema comercial no ha dejado de ser parte de la agenda, y así lo evidencia la aprobación del Código Aduanero. La existencia de conflictos comerciales no se puede negar y ciertamente expresa que existen problemas en el proceso de integración, pero tampoco significa su fracaso. Si aceptamos ese argumento, en algún momento se hubiese podido el fracaso del TLCAN porque no se había autorizado el libre tránsito de camiones mexicanos en Estados Unidos, que debía estar en vigor en 1995, pero que solo se aplica a partir de 2011. Esto nos conduce a una tercera reflexión, que es la necesidad de evaluar un proceso complejo como el Mercosur en todas sus dimensiones y no solo a partir de una variable como la intensidad de la interdependencia, pues de lo contrario tendríamos una «fotografía distorsionada» del proceso de integración, que simplemente expresaría una preferencia metodológica o incluso una opción política.

Sin embargo, es preciso considerar algunas de las críticas al proceso de revisión del modelo del Mercosur. Por ejemplo, deben establecerse criterios realistas al introducir elementos del modelo de regionalismo social. Así, existe un amplio debate sobre la forma en que la integración regional puede ayudar a resolver los problemas de la pobreza y la exclusión social (véase Te Velde, 2006). El modelo de regionalismo social reconoce que la integración puede cumplir un papel importante en tal proceso. No obstante, no puede presumirse que la integración regional va a resolver los problemas sociales de los países de la región, pues esto continua siendo esencialmente un esfuerzo nacional. Esto es parte de lo que Aldo Ferrer describe como densidad nacional, uno de cuyos elementos es la cohesión social. En palabras de Ferrer (2007: 149), «el avance de la integración depende en gran medida de materias propias de la situación interna de los países y que solo tienen solución dentro de cada 
José BRICEÑo RuIZ • Ejes y modelos de la etapa actual de la integración económica...

espacio nacional. Tales, por ejemplo, las políticas sociales para elevar el nivel de vida y ampliar el mercado interno...». Teniendo en cuenta esto, y considerando que ni siquiera la Unión Europea ha logrado establecer una política social regional de carácter supranacional, la inclusión de elementos del modelo de regionalismo debe ser un proceso realista, con objetivos realmente realizables, de lo contrario se terminará dando razón a quienes argumenta que se trata solo de retórica.

Es claro entonces que el Mercosur ha transformado su agenda de integración para incluir además de los temas comerciales, objetivos sociales y preocupaciones neo-desarrollistas, lo que refleja que "existe una creciente aceptación que el bloque necesita medidas estructurales más profundas para sobrevivir y superar el riesgo de descomposición» (Celli, Marcus, Tussie y Peixoto, 2011: 52). La adopción de estas medidas estructurales implica superar el modelo de regionalismo estratégico. Por ello, lo definimos como un «eje revisionista", que no plantea ni un retorno al proteccionismo ni una ruptura con el sistema mundial de comercio, sino que se propone superar las limitaciones que ha tenido la integración en aspectos como el tratamiento de las asimetrías, la transformación productiva y la equidad en la distribución de las ganancias y pérdidas de la integración, elementos no previsto en la pura lógica competitiva del modelo de regionalismo estratégico. En términos de modelo, esto ha significado que el Mercosur constituya actualmente un complejo proceso de integración, una suerte de "hibrido» en el cual existen objetivos, instrumentos e instituciones de los modelos de regionalismo estratégico, regionalismo social y regionalismo productivo (véase la figura 2)

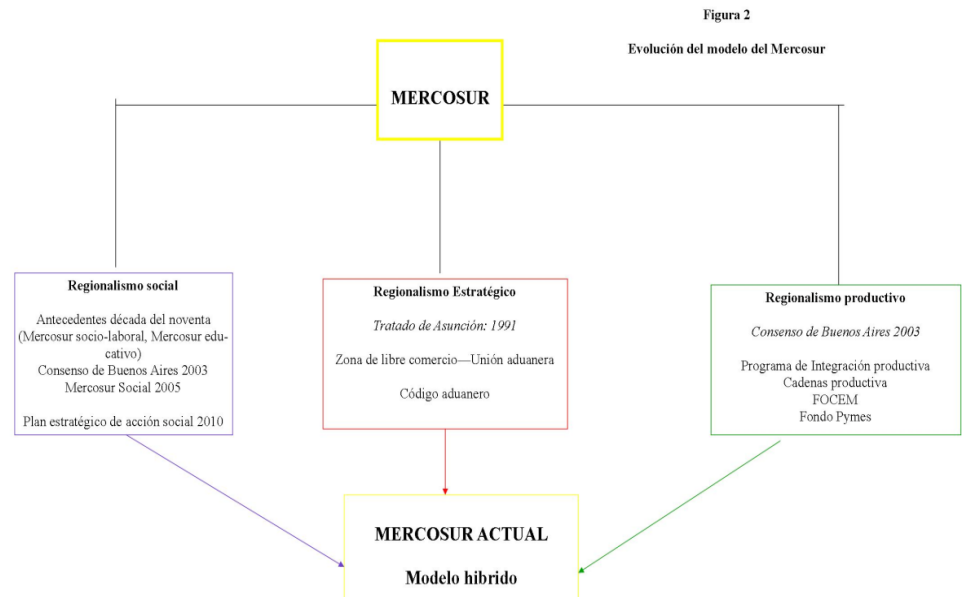


3.2 El modelo del eje de integración abierta

El eje de la integración abierta adopta buena parte de las premisas del modelo de regionalismo estratégico. Sin embargo, a diferencia del modelo del Mercosur previsto en el Tratado de Asunción, en este eje se ha adoptado por formas de integración norte-sur y una agenda de integración profunda. La razón de esta situación es que este eje se construyó en torno a la firma de TLC bilaterales, cuyo fundamento es el TLCAN.

La firma de los TLC ha sido parte de un intenso debate en la región. En América Latina se ha argumentado que los TLC profundizan la naturaleza asimétrica de las negociaciones comerciales hemisféricas y reducen la posibilidad de acuerdos comerciales recíprocos (Bouzas, 2005: 17). También se argumenta que en los TLC se ha cedido en disciplinas y estrategias de desarrollo "comprometiendo no sólo el manejo de recursos estratégicos sino el propio control de los mismos, dadas las concesiones en inversiones y solución de controversias» (Fairlie, 2006: 193). También se alega que los TLC pueden afectar los procesos subregionales de integración, la mayoría de los cuales están en la etapa de unión aduanera. Como los tratados han sido finalmente suscritos por cada país en forma individual y no por los esquemas regionales actuando como grupos, esto implicaría perforar la unión aduanera y diluir las posibilidades de una política comercial común. Además, para los esquemas de integración que pretenden convertirse en mercados comunes, los TLC crean un marco normativo en sectores como la propiedad intelectual, servicios e inversiones adaptados al «modelo TLCAN», sin respetar la normativa subregional existente o, en el caso de que no existan avances en estas áreas, imponiéndola de antemano. Esto habría generado una irrelevancia de los procesos de integración regional o profundas crisis internas en estos estos, como en el caso de la Comunidad Andina (CAN), en la cual se produjo una división entre sus miembros sobre la conveniencia de suscribir un TLC con Estados Unidos. Esta fue la razón alegada por el gobierno de Hugo Chávez en Venezuela para retirarse de la CAN en 2006 y explica la actual división de este bloque en un eje Bogotá-Lima y otro Quito-La Paz.

En términos de modelos de integración, los cuatro TLC hasta ahora suscritos entre los países latinoamericanos son nítida expresión del «modelo TLCAN». Del análisis del contenido de los acuerdos suscritos por Estados Unidos con Chile, América Central y República Dominicana, Perú y Colombia, puede observarse que buena parte de las normas y disciplinas del TLCAN y de las propuestas del ALCA sirvieron de base a los TLC. Por ejemplo, el TLCAN, como el proyecto del ALCA, se basa en los principios de trato nacional, que se transformó en trato local (en el sentido de limitar la capacidad de los gobiernos locales o regionales de establecer algún tipo de medida de apoyo regional o 
José BRICEÑo Ruiz • Ejes y modelos de la etapa actual de la integración económica...

sectorial) y transparencia (Estay y Daza, 2005: 51). En términos de acceso a los mercados, en el TLCAN se propone la creación de una amplia zona de libre comercio para la totalidad del universo arancelario mediante un proceso de liberalización arancelaria lineal a través del mecanismo de las listas negativas, con un universo arancelario significativo desgravado en la fase inicial del proceso de integración. Estos principios y esta metodología de liberalización comercial se propuso para el fallido ALCA y fueron luego incorporados en los TLC suscritos por Estados Unidos con los países de América Latina (Cf. Briceño Ruiz, 2009).

La agenda no arancelaria de los TLC es la típica de un acuerdo de «integración profunda» como la promovida por el modelo TLCAN. Es evidente la similitud de temas con relación a los negociados en el ALCA. Este es un aspecto central de la estrategia de Estados Unidos, que ofrece una apertura de su mercado a cambio de la adopción de normas «OMC plus» en temas relevantes, algunos de los cuales ni siquiera han sido negociados en el ámbito de la OMC. En este sentido, los temas no arancelarios de los TLC bilaterales son exactamente los mismos promovidos en la «Agenda Singapur», ya regulados en el TLCAN y que pretendieron ser normados en el ALCA. En concreto, estos temas son las inversiones, los servicios, las compras gubernamentales y la propiedad intelectual. Los países latinoamericanos han aceptado compromisos OMC plus que suponen disciplinas más exigentes que las que están vigentes en el plano multilateral. Contrasta en cambio la escasa regulación a las cuestiones no arancelarias relativas al acceso a los mercados. En concreto, no existe normativa para regular las normas anti-dumping y los derechos compensatorios, mecanismos de protección para-arancelaria bastante utilizados por Estados Unidos. Como en el caso del ALCA, el tema de los subsidios y apoyos a la agricultura tampoco es regulado en los TLC (Briceño Ruiz, 2009).

La Alianza del Pacífico también adoptó el «modelo TLCAN». Dos elementos distintivos de ese modelo de integración están presentes en el nuevo bloque regional: su carácter exclusivamente comercial y abierto, y su agenda de «integración profunda». La Alianza del Pacífico asume estas dos premisas. En la Declaración Presidencial del encuentro de Lima en abril de 2010, se señala de forma expresa el compromiso con el libre comercio. Al respecto se asevera que los acuerdos de libre comercio «ofrecen una excelente plataforma que facilita y propicia la integración de nuestras economías; y (...) reafirmando que los acuerdos que alcancemos en el marco de esta iniciativa deberán contribuir y profundizar los acuerdos económicos, comerciales y de integración que nuestros países hayan suscrito a nivel bilateral, regional y multilateral» (Declaración presidencial sobre la Alianza del Pacífico, 28 de abril de 2011). Este objetivo fue ratificado en el Acuerdo Marco firmado en $\mathrm{Pa}$ - 
ranal, Antofagasta, en junio de 2012, en el cual se expresa la convicción de fortalecer los acuerdos de integración como «espacios de concertación y convergencia, orientados a fomentar el regionalismo abierto, que inserte a las partes eficientemente en el mundo globalizado y las vincule a otras iniciativas de regionalización» (Acuerdo Marco del Alianza del Pacifico, Preámbulo).

La Alianza del Pacífico plantea la meta de lograr la convergencia de los acuerdos comerciales existentes en un bloque regional que se propone una acción conjunta para influenciar en la dinámica político-económica de la región. La idea es reemplazar por un solo acuerdo comercial la diversidad de acuerdos existente entre los países de la Alianza: «Colombia con México en el G-2 (que sustituyó el G-3 ante el retiro de Venezuela); Colombia con Chile en dos acuerdos comerciales de 1994 para bienes y de 2007 para servicios y otras reglas de comercio exterior; Chile con México, Chile con Perú, y el libre comercio entre Colombia y Perú, reglamentado en el proceso de la Comunidad Andina de Naciones (CAN)» (Viera Posada, 2011). Por otro lado, también se propone avanzar más allá de la zona de libre comercio, pues se plantea «avanzar progresivamente hacia el objetivo de alcanzar la libre circulación de bienes, servicios, capitales y personas» (Declaración presidencial sobre la Alianza del Pacífico, 28 de abril de 2011). En la teoría de la integración esto último supone avanzar hacia la creación de un mercado común, fase en la cual se promueve la libre circulación de factores productivos (capitales, servicios, personas).

Luego de casi dos años de haberse creado la Alianza, no se ha logrado aún homologar los acuerdos previos ni crear una zona de libre comercio. No obstante, en la XXII Cumbre Iberoamericana realizada en Cádiz, España, en noviembre de 2012, se produjo un encuentro de los Presidentes de la Alianza del Pacífico. En su Declaración Final «refrendaron su compromiso de concluir la negociación en materia de Acceso a Mercados durante el primer cuatrimestre de 2013» (Declaración Conjunta de los Presidentes de la Alianza del Pacífico, Cádiz, España, 17 de noviembre de 2012).

La Alianza del Pacífico se mantiene apegada a la «agenda de integración profunda", algo que se reconoce en la Declaración de Lima, cuando los presidentes acuerdan crear un "área de Integración Profunda mediante un proceso de articulación política, económica y de cooperación e integración en América Latina» (Declaración de Lima, abril 2011). Aunque en la Declaración de Lima no se establece el compromiso de suscribir normas OMC plus sobre los temas de integración, esto es comprensible porque los cuatro países miembros (Colombia, Chile, Perú y México) ya han adoptado este tipo de normas, la mayoría de ellas en los tratados bilaterales de libre comercio que han suscrito con Estados Unidos. En consecuencia, lo que puede acontecer es una convergencia de esta normativa 
José Briceño RuIZ • Ejes y modelos de la etapa actual de la integración económica...

OMC plus en el Acuerdo Marco que se propone homologar los acuerdos ya existentes, como se prevé en la Declaración de Lima. Destaca, no obstante, que se adopte la expresión «integración profunda» para describir al bloque regional. En la Declaración de Lima esta se amplía para referirse al movimiento de personas y de negocios, facilitación del tránsito migratorio, cooperación judicial, facilitación del comercio y cooperación aduanera, servicios, capitales, incluyendo la posibilidad de integrar las bolsas de valores (Declaración de Lima, abril de 2011).

Como se ha demostrado en esta sección, el «modelo TLCAN» es el fundamento orientador tanto de los TLC bilaterales como de la recién creada Alianza del Pacífico. Existe en consecuencia una relación directa entre el eje del regionalismo abierto y la estrategia regionalista promovida por Estados Unidos, pues existe una relación directa en términos de agenda, instrumentos y disciplinas entre lo acordado en el TLCAN y la Alianza del Pacífico (véase figura 3).

Figura 3

Secuencia del modelo de eje del regionalismo abierto

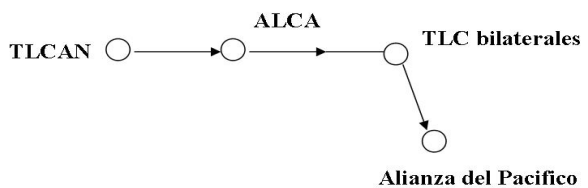

Ahora bien, mientras los TLC son un claro ejemplo de regionalismo estratégico norte-sur, la Alianza del Pacífico se presenta como un modelo más difícil de catalogar, pues aunque incluye un amplia liberalización comercial y una agenda de integración profunda con compromisos OMC plus, se trata sin embargo, de un acuerdo sur-sur (véase figura 4). Además, un elemento central del modelo de regionalismo estratégico es la exclusión de sectores considerados «importantes» (la energía en el TLCAN, los automóviles en el Mercosur). No existe aún un acuerdo de libre comercio de la Alianza y por ello no es posible delimitar si algunos sectores estratégicos serán excluidos del proceso. No obstante, si el acuerdo se llega a basar en el modelo TLCAN es posible que se adopte un modelo de regionalismo estratégico. Si esto sucede, puede emerger una nueva categoría en la tipología de acuerdos basados en el regionalismo estratégico. Esta no se asimilaría ni al TLCAN (ejemplo de regionalismo estratégico norte-sur) o al Mercosur del Tratado de Asunción (ejemplo de regionalismo estratégico sur-sur). Esta nueva modalidad representanda por la Alianza del Pacífico (regionalismo estratégico sur-sur con agenda de integración profunda OMC plus) constituye un anomalía en uno de los tres tipos ideales propuesto en la sección 2 de este trabajo. 
Figura 4

El modelo de eje del regionalismo abierto

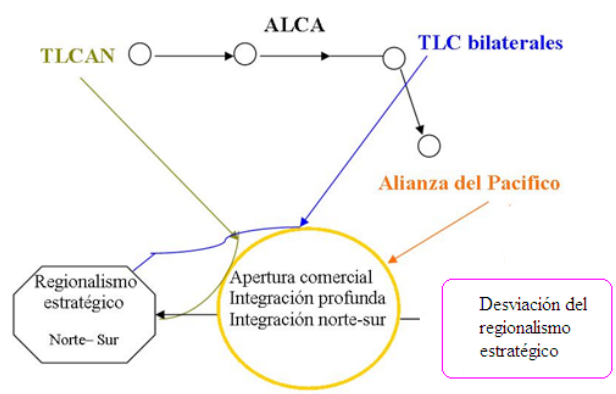

Sin embargo, como señaló Max Weber, los tipos ideales son construcciones mentales o, en sus palabras, «utopías racionales", que es imposible encontrar empíricamente en toda su pureza (cf. Weber, 2003). En consecuencia, es posible encontrarnos con aspectos de la realidad que no coinciden exactamente con un tipo ideal. En sociología, el concepto de desviación sirve para explicar algún tipo de comportamiento que se aleja de un tipo ideal. Sin embargo, la existencia de desviaciones del tipo ideal no destruye la función heurística de este, evitando además una ampliación ex post facto de la tipología original.

Si tomamos en cuenta estas consideraciones, la Alianza del Pacífico representa una desviación que deriva esencialmente del hecho de que a pesar de ser un acuerdo sur-sur se promueva una agenda de integración profunda con acuerdos OMC plus. Esto sería más propio de la variante norte-sur del modelo de regionalismo estratégico. Esta desviación se explica por el hecho de que los miembros de la Alianza del
Pacífico ya han suscrito TLC con países del Norte donde se han aprobado normas OMC plus. En consecuencia, para estos países simplemente se trata de lograr convergencia de una normativa ya vigente desde hace varios años. Salvo esta anomalía, la Alianza se ajusta a los parámetros del modelo de regionalismo estratégico.

\subsection{El modelo del eje antisistémico del ALBA}

Existe un debate sobre si el eje antisistémico representado por el ALBA puede ser catalogado como un proceso de integración económica. Desde el punto de vista de la teoría liberal, el ALBA no es un proceso de eliminación de barreras ni que se realiza de forma gradual a partir de una zona de libre comercio hasta la unión económica. La cuestión es que el ALBA pretende ser un nuevo modelo que rompe con esta lógica de integración. En este sentido, la experiencia europea no es un modelo para el ALBA. El modelo de integración del TLCAN tampoco se relaciona con el ALBA pues este incluso nace como alternativa al ALCA, propuesta de integración inspirada a su vez en el acuerdo suscrito en América del Norte. Esto nos lleva a un tema crucial para entender al ALBA: esta se presenta como un modelo alternativo de integración (Regueiro Bello, 2008) o como una «forma de integración que no parte de lo mercantil» (Bossi, 2005). En este sentido, el actualmente se define como un modelo de integración no capitalista. 
José Briceño RuIZ • Ejes y modelos de la etapa actual de la integración económica...

No obstante, aunque el ALBA se describe como «un modelo no capitalista", tampoco se dan muchos detalles de este modelo. El único modelo no capitalista de integración conocido en el mundo ha sido el Consejo de Ayuda Mutua Económica (CAME o Comecon), que agrupaba a los países del antiguo bloque soviético. Aunque en el ALBA existen mecanismos como el comercio compensado y ciertas formas de bilateralismo que la asemejan al Comecon, este tenía características como la planificación económica que están ausentes en el ALBA.

El ALBA tampoco se basa en las premisas cepalistas de una integración al servicio de la industrialización regional. En la óptica de los promotores del ALBA este esquema regional no podía basarse en las propuestas estructuralistas-cepalistas porque estas concedían un papel importarte a las «burguesías industrializantes» (Martínez, 2006a: 13). Estas últimas habrían sido arrasadas por el neoliberalismo y se habrían estructurado en torno a la liberalización y especulación financiera y al servicio de las ETN (Martínez, 2006a: 13). El ALBA sería entonces un nuevo modelo de integración. Esta iniciativa de integración sería «una respuesta contestataria, propositiva y alternativa real frente al capital, en tanto construye un tipo de integración no articulado por las empresas transnacionales, el mercado, el comercio, como lo hizo la integración que precedió el ALBA -integración cepalina e integración neoliberal- sino que está trabajando por colocar el desarrollo bumano como su objetivo supremo» (Pérez García, 2010: 49; cursivas en el original).

La división tradicional formulada por Bela Balassa de las etapas de la integración regional, que van gradualmente de una zona de libre comercio a una unión económica, no existen en el ALBA. En vez de ello, el ALBA se basa en la idea de que la integración no puede reducirse al comercio, "ni medir sus avances por el crecimiento del intercambio comercial», ni «encerrarse entre las rejas» del libre comercio. Por ello, no se propone abolir el comercio sino reafirmar que la integración «es mucho más que hacer comercio y que incluso no puede contentarse la integración verdadera con cualquier clase de comercio» (Martínez, 2006b: 78).

Se admite entonces el comercio como componente del proceso, pero este debe estar sometido a los objetivos de desarrollo del proceso de integración. Esto implica formas de comercio compensado y mecanismos para favorecer a los países más débiles mediante precios preferenciales o comercio de trueque (Martínez, 2006: 79). Este nuevo modelo de integración promovería un comercio más bien basado en las «ventajas cooperativas», en vez de apoyarse en la lógica tradicional de las ventajas comparativas. Igualmente, el ALBA se basaría en instrumentos de compensación entre los países, que en vez de ganar y vender bajo una lógica de ganancia comenzarían a comerciar en función de lo que un país produce y necesita (véase Sader, 2006). 
Inicialmente, la mayor parte de la agenda y los instrumentos desarrollados por el bloque regional se concentraron en la cooperación energética (Petrocaribe, Petrosur) y los intentos de internacionalizar los programas sociales que en Venezuela se denominaron Misiones. No obstante a partir de 2007 comenzaron a aprobarse instrumentos de tipo económico como un mecanismo de pago para las transacciones comerciales (el denominado Sistema Unitario de Compensación Regional-SUCRE-), mecanismos financieros como el Banco del ALBA y la cooperación en materia productiva (la creación de empresas grannacionales). Como se puede observar, comienza a desarrollarse una agenda de integración económica, pese a que el comercio no era parte del proyecto de integración. Esto se pretende consolidar en febrero de 2012, cuando se decidió crear el denominado espacio económico del ALBA-TCP (ECOALBA-TCP) que se propone incrementar el grado de interdependencia económica y comercial entre los países del ALBA. No obstante, esto no se pretende lograr promoviendo la creación de una zona de libre comercio o adoptando formas tradicionales de integración comercial. Según el Acuerdo creador del ECOALBA-TCP, este se concibe como "como una zona económica de desarrollo compartido interdependiente, soberana y solidaria, destinada a consolidar y ampliar un nuevo modelo alternativo de relacionamiento económico para fortalecer y diversificar el aparato productivo y el intercambio comercial, así como es- tablecer las bases para los instrumentos de carácter bilateral y multilateral que las Partes suscriban en esta materia, con miras a la satisfacción de las necesidades materiales y espirituales de nuestros pueblos» (Acuerdo para la Constitución del Espacio Económico del ALBA-TCP (ECOALBA-TCP), 2012).

En consecuencia, se puede describir al ALBA como esquema de integración que adopta las premisas de los modelos social y productivo. Es notorio que el ALBA, como expresión de un eje antisistémico que es crítico del orden mundial existente, difícilmente puede plantearse como meta insertarse en los mercados globales a partir de una plataforma de integración regional. En vez de ello, intenta fomentar instrumentos para el desarrollo productivo conjunto, como serían las denominadas Empresas Grannacionales. Estas se orientarán «a privilegiar la producción de bienes y servicios para la satisfacción de las necesidades humanas garantizando su continuidad y rompiendo con la lógica de la reproducción y acumulación del capital» (Secretaría Ejecutiva del ALBA - TCP, 2010a: 1). Se trata de «empresas de los países del ALBA integradas productivamente, cuya producción se destinará fundamentalmente al mercado intra-ALBA, para configurar una zona de comercio justo y cuya operación se realice de manera eficiente (Secretaría Ejecutiva del ALBA - TCP, 2010a: 1). A esta política de integración productiva se sumaba un conjunto de propuestas en el área social. En un documento 
José BRICEÑo RuIZ • Ejes y modelos de la etapa actual de la integración económica...

reciente de la Secretaría Ejecutiva del ALBA - TCP se la describe como una alianza para combatir la exclusión social. En este sentido, propone un modelo social de desarrollo que "concentra los esfuerzos en áreas prioritarias como son la educación, salud, alimentación, medio ambiente, cultura, energía y tecnología» (Secretaría Ejecutiva del ALBA - TCP, 2010b: 2).

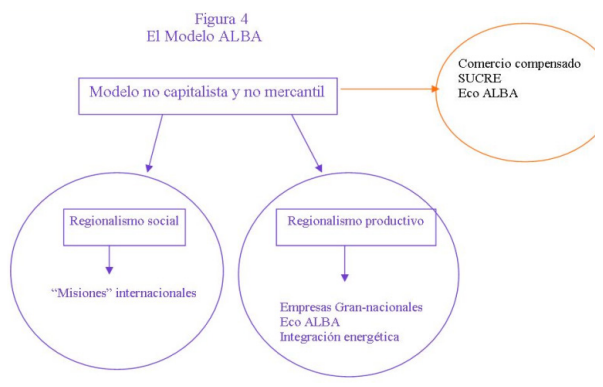

\section{Conclusiones}

La integración económica regional en América Latina atraviesa por un nuevo periodo que se caracteriza por el fin de la hegemonía del enfoque de integración abierta y vinculada a la reforma económica neoliberal imperante en la década de 1990. A esto se suma la creciente heterogeneidad regional en términos de la comprensión que los diversos actores estatales y no estatales tienen sobre cuál modelo de integración debe ser adoptado en esta nueva fase del regionalismo latinoamericano. Como consecuencia, se observa por un lado una proliferación de iniciativas que incluyen esquemas de cooperación y concertación política, cooperación económica e integración regional, todas ellas parte de un cada vez más diverso regionalismo latinoamericano; por el otro, se percibe el surgimiento y consolidación de ejes de integración económica regional que han adoptado distintos modelos económicos para organizar los espacios subregionales en construcción.

Es evidente la fragmentación subregional de la integración latinoamericana al menos en tres ejes: un eje de integración abierta, representado por la Alianza del Pacífico y los TLC; un eje revisionista, cuya manifestación es el denominado «nuevo Mercosur»; y un eje antisistémico personificado por el ALBA. Estos tres ejes de integración han adoptado modelos de integración económica muy diversos. Mientras el Mercosur revisa su modelo de regionalismo estratégico plasmado en el Tratado de Asunción y lo amplia con políticas de regionalismo social y regionalismo productivo, el ALBA pretende ser un nuevo modelo de integración no basado en el comercio y la ganancia mercantil sino en la solidaridad la complementación y la cooperación. La Alianza del Pacifico, por su parte, reivindica las políticas de regionalismo abierto, incluso apoyando una estrategia de integración que favorece una agenda más propia de iniciativas de tipo norte-sur.

Este escenario fragmentado de la integración económica regional expresa la cartografía de los cambios políticos ocurridos en América Latina. Mientras que los gobiernos de orientación más 
conservadora defienden el modelo de la década de 1990, los gobiernos de los ejes revisionista y antisistémico expresan la orientación hacia la izquierda de los gobiernos de sus países miembros. Ahora bien, mientras que países como Argentina, Brasil y Uruguay han impulsado una revisión de elementos de la estrategia de integración de 1990, los miembros del ALBA se proponen una ruptura con las formas tradicionales de integración económica basadas en el libre comercio. En este contexto, la vieja idea de construir un mercado regional latinoamericano (el mercado común que Prebisch propuso en los años 1950) es cada vez más lejana.

Existen otros elementos que destacan de esta nueva realidad regional. Algunos de ellos son contradictorios pues en el ámbito político y funcional del regionalismo se observan iniciativas innovadoras como la UNASUR y la Comunidad de Estados de América Latina y el Caribe (CELAC). Igualmente, se observan contradicciones en el eje ALBA, debido al reciente ingreso de Venezuela al Mercosur; la presencia de Nicaragua en ese bloque a pesar de ser parte del CAFTA-DR o la aún presencia de Colombia y Ecuador en la muy debilitada Comunidad Andina, que junto con el Sistema de Integración Centroamericano son dos "viejos ejes» que tratan de mantenerse a pesar de la creciente preferencia de sus miembros por ser parte de los nuevos ejes surgidos en los años 2000.

Aunque complejo y contradictorio, el escenario descrito en este artículo demuestra la persistencia del regionalismo latinoamericano en general y de las iniciativas de integración económica en particular. A pesar de la heterogeneidad política regional y las limitaciones que desde fines de la década de 1990 mostraron las iniciativas en marcha, la integración persiste. Incluso países como Chile, que los años 1990 se negó a ser parte de algún esquema económico regional en América Latina, ahora es fundador de la Alianza del Pacífico.

\section{Bibliografía}

Abreu, Sergio (2005), La fuga hacia adelante, Diario el País, 24 de octubre. Disponible en: http://www.sergioabreu.com/artfuga. html. Consultado el 14 de enero de 2013.

Acuerdo Marco del Alianza del Pacifico, suscrito en Paranal, Antofagasta, Chile, el 16 de junio de 2012.

Almeida, Paulo Roberto de (2007), Sete teses impertinentes sobre o MERCOSUL. Disponible en: Via Política, Brasilia, $14 \mathrm{de}$ marzo de 2007, en http://www.viapolitica. com.br/diplomatizando view.php?id diplomatizando $=36$. Consultado el 18 de enero de 2013.

Acuerdo para la Constitución del Espacio Económico del ALBA-TCP (ECOALBA-TCP) (2012). Consejo de Complementación Económica del ALBA (03 de febrero de 2012). XI Cumbre - Caracas, Venezuela -04 y 05 de febrero de 2012, http://www.alba-tcp.org/contenido/consejo-de-complementacion-economica-del-alba-03-de-febrero-de-2012-1. Consultado el 29 de abril de 2011.

Axline, Andrew (1999), «El TLCAN, el Regionalismo Estratégico y las Nuevas Direcciones de la Integración Latinoamericana», en Briceño Ruiz, José (ed.), Escenarios de la integración Regional en 
José BRICEÑo Ruiz • Ejes y modelos de la etapa actual de la integración económica...

las Américas, Mérida: Universidad de los Andes, pp. 11-74.

Baumann, Renato (2011) «El Mercosur a los veinte años. Una evaluación económica», en Briceño Ruiz, José (editor), El Mercosur y las complejidades de la integración regional, Buenos Aires: Teseo, pp. 165-201.

Bizzozero, Lincoln (2011), "Los primeros veinte años del Mercosur: del programa de liberación comercial al Plan Estratégico de Acción Social», Densidades, Buenos Aires, $\mathrm{N}^{\mathrm{o}}$ 6, mayo, pp. 23-34

Bouzas, Roberto, Pedro da Motta Veiga y Sandra Rios, "Crisis y perspectivas de la integración en América del Sur», en Lagos, Ricardo (compilador), América Latina: ¿Integración o fragmentación? , Buenos Aires: Edhasa, pp. 319-347.

Brander, James A (2005), Strategic Trade Policy, NBER Working Paper Series, no. W5020, Cambridge, Massachusetts, febrero.

Briceño Ruiz, José (2001), «De la integración autonómica al regionalismo abierto: crisis y resurgimiento del regionalismo latinoamericano", Cuadernos Americanos, UNAM, Vol. 5, $\mathrm{N}^{\circ}$. 89, septiembre-octubre, pp. 98-128.

Briceño Ruiz, José (2007), La integración regional en América latina y el Caribe. Proceso históricos y realidades comparadas, Mérida: Vice Rectorado Académico, Universidad de los Andes.

Briceño Ruiz, José (2009), «Estados Unidos y el nuevo regionalismo en las Américas. Del TLCAN a los TLC», en Guerra Borges, Alfredo (coord.), Fin de época: de la integración tradicional al regionalismo estratégico, México: Siglo XXI, pp. 155-186.

Briceño Ruiz, José (2011), «El ALBA como propuesta de integración regional», en Josette Altmann Brobón (editora), ALBA ¿Una nueva forma de integración regional?, Buenos Aires: Editorial Teseo FLACSO, pp. 19-83.

Briceño Ruiz, José (2012), «La alianza del Pacífico: la viabilidad de un naciente bloque regional», en Ardila, Martha (ed.), El pacífico latinoamericano y sus rela- ciones con la región Asia Pacífico, Bogotá: Universidad Javeriana, 2012, pp. 113-157. Brodie, Bernard (2008), «Strategy as science», en Mahnken, Thomas G. y Joseph A., Maiolo, (eds.); Strategic Studies, Londres: Routledge, 2008, pp. 8-21.

Buck, Karl (2010), "The European and Latin American Integration Projects», en Stemplowski , Ryszard (red.), Europe and Latin America - Looking at each other?, Varsovia: The Polish Institute of International Affairs, pp. 383-413.

Celli, Umberto, Marcus Salles, Diana Tussie y Juliana Peixoto (2011), Mercosur in South - South Agreements: in the middle of two models of regionalism, Documento de Trabajo no. 59, Area de Relaciones Internacionales, Buenos Aires: FLACSO Argentina, junio.

CEPAL (1959), El Mercado Común Latinoamericano, Santiago, CEPAL.

Coulomb, Fanny. Economic Theories of Peace and War, Londres: Routledge, 2004.

Declaración Conjunta de los Presidentes de la Alianza del Pacífico, Cádiz, España, 17 de noviembre de 2012

Deacon, Bob, Isabel Ortiz y Sergei Zelenev (2007), Regional Social Policy, DESA Working Paper No. 37 ST/ESA/2007/ DWP/37, , Nueva York, N.Y. :United Nations Department of Economic and Social Affairs, junio.

Estay, Jaime y German Sánchez (2005), «Una revisión general del ALCA y sus implicaciones», en Estay, Jaime y Gérman Sánchez (coord.), El ALCA y sus peligros para América Latina, Buenos Aires: CLACSO, pp. 17-106.

Ferrer, Aldo (2007), «El éxito del Mercosur posible», Revista de Economía Política, Vol. 27, $\mathrm{N}^{\mathrm{o}} 1$ (105), enero-marzo, pp. 147-156

Giacalone, Rita (1999), El Grupo de los Tres. Análisis de su Dimensión Politica y Económica, Caracas: Panapo.

Gutiérrez, Alejandro. (1999), «La Comunidad Andina de Naciones: el difícil camino de la integración regional», en Briceño, Ruiz, 
José (comp.). Escenarios de la Integración Regional en las Américas, Mérida: Universidad de Los Andes, pp. 265-312.

Hettne Björn y Söderbaum Fredrik (2000), "Theorising the Rise of Regionness", New Political Economy, Vol. $5 \mathrm{~N}^{\circ}$ 3, pp. 457-472

Katz, Claudio (2006), El rediseño de América Latina. ALCA, Mercosur y ALBA, Buenos Aires: Ediciones Luxemburg.

Lawrence, Robert Z. (1996), Regionalism, Multilateralism and Deeper Integration, Nueva York: The Brookings Institution.

Malamud, Andrés (2005), "Mercosur turns 15: Between rising rhetoric and declining achievement", Cambridge Review of International Affairs, Vol. 18, $\mathrm{N}^{\circ} 3$, pp. 421-436

Marchal, André (1970), Integración y Regionalización de la Economía Europea, Madrid: Seminarios y Ediciones S.A.

Martínez, Osvaldo (2006a), «ALBA o ALCA: El dilema de la integración», Temas de la economía mundial, La Habana, Nueva Epoca II, No 9, febrero, pp. 4-21.

Martínez, Osvaldo (2006b), «ALBA y ALCA: el dilema de integración o la anexión», Cuadernos África - América Latina, Madrid, $\mathrm{N}^{\circ}$ 40-41, primer semestre, pp. 66-87

Mercier, David (2000), "Le régionalisme stratégique dans les Amériques : tenants et aboutissants de I'ALÉNA vus d'une perspective mexicaine (Note)», Études internationales, Vol. 31, No 1, pp. 115-116.

Pérez García, José Antonio (2010), «ALBA: construyendo alternativas de los pueblos. Resultados, tensiones y desafíos", Temas de economía mundial, La Habana, Nueva Epoca 2, $\mathrm{N}^{\mathrm{o}} 10$, septiembre, pp. 48-74.

Perroux, François (1966), "Intégration économique. Qui intègre ? Au bénéfice de qui s'opère l'intégration ? ", Économie appliquée, Vol. XIX, No 3-4, julio-diciembre, pp. 389-414.

Prebisch , Raul (1959), «El Mercado Común Latinoamericano», Comercio Exterior, Vol. IX, № 9, septiembre, pp. 509-513.

Richardson, J. David (1990), «The Political Economy of Strategic Trade Policy», In- ternational Organization, Vol. XLIV, $\mathrm{N}^{\circ}$ 1, invierno, pp. 107-135.

Rigirozzi, Pia (2012), Regionalism through social policy and policy action: rescaling responsibilities and rights, disponible en: http://www.southampton.ac.uk/C2G2/ media/2012\%20Discussion\%20Papers/ Riggirozzi\%20(2012).pdf. Consultado el 18 de enero de 2012.

Rigirozzi, Pia (2010), Region, Regioness and Regionalism in Latin America. Towards a new Synthesis, LATN Working Paper $\mathrm{N}^{\mathrm{o}} 130$, abril.

Russell, Roberto (2011), "América Latina ¿Entre la integración y la polarización?, Un falso dilema», en Wollrad, Dörte, Günther Maihold y Manfred Mols (eds), La agenda internacional de América Latina: entre nuevas y viejas alianzas, Buenos Aires: Nueva Sociedad, Fundación Friedrich Ebert, Stiftung Wissenschaft und Politik, pp. 123-138.

Sanahuja, José Antonio (2010), «La construcción de una región: Suramérica y el regionalismo postliberal», en Cienfuegos, Manuel y José Antonio Sanahuja (eds.), Una región en construcción. UNASUR y la integración en América del Sur, Madrid: Fundación CIDOB, pp. 87-136.

Schelhase, Marc (2011), "The Success, Failures and Future of Mercosur», en Mace, Gordon, Andres F. Cooper y Timothy M. Shaw (eds.), Inter-American Cooperation at a Crossroads, Houndmills: Palgrave Macmillan, pp. 171-186.

Secretaría Ejecutiva del ALBA - TCP (2010a), Grannacional en el marco del ALBA, Caracas: Secretaría Ejecutiva del ALBA - TCP.

Secretaría Ejecutiva del ALBA - TCP (2010b) La inclusión social de los pueblos del ALBA-TCP. Generando espacios de igualdad, bienestar social y superación de la pobreza, Caracas: Secretaría Ejecutiva del ALBA - TCP.

Sunkel, Osvaldo (1991), El desarrollo desde dentro. Un enfoque neo-estructuralista para América Latina, México: Fondo de Cultura Económica. 
José BRICEÑo RuIZ • Ejes y modelos de la etapa actual de la integración económica...

Te Velde, Dirk Willem (ed.) (2006), Regional Integration and Poverty, Aldershot: Ashgate.

United Nations Conference on Trade and Development (UNCTAD) (2007), Regional Cooperation for Development, Trade and Development Report 2007, Nueva York - Ginebra: United Nations.

Vázquez, Mariana (2011), «El Mercosur social. Cambio político y nueva identidad para el proceso de integración regional en América del Sur», en Caetano, Gerardo (ed.), Mercosur 20 años, Montevideo: CEFIR, pp. 165-185.

Veiga, Pedro da Motta y Sandra Rios (2006). 'América do Sul: A integração pode sobreviver ao nacionalismo econômico?' Latin America Trade Network, FLACSO Serie Brief, $\mathrm{N}^{\circ} 32$, julio.

Viera Posada, Edgard (2011), «Los escenarios de la alianza del Pacífico, el Alba y Unasur», Perspectivas, no. 26, julio, disponible en http://www.revistaperspectiva.com/ new detalle. 